\title{
The Establishment of a Smart Growth Evaluation System Weibiao Du
}

\author{
School of North China Electric Power University, Baoding 071000, China \\ 1019425754@qq.com
}

Keywords: Smart growth, Index system

\begin{abstract}
The world is rapidly urbanizing, and urban planning is becoming more important. Smart growth is a planning theory that can realize the sustainable development of the city effectively. In this paper, we study the principles of smart growth and set up a complete index system.
\end{abstract}

\section{Introduction}

"Smart growth is about helping every town and city become a more economically prosperous, socially equitable, and environmentally sustainable place to live.”[1] It is projected that by 2050, 66 percent of the world's population will be urban. This is to say the world is rapidly urbanizing. Consequently, urban planning has become increasingly important and necessary to ensure that people have access to equitable and sustainable homes, resources and jobs. Smart growth focuses on building cities that embrace the E's of sustainability-Economically prosperous, socially Equitable and Environmentally Sustainable. Such we set up a complete index system to measure the degree of smart growth.

\section{Our Index System}

Based on AHP, we define a multi - index extension comprehensive evaluation method [2], which is based on the matter - element theory of extension and extension mathematics.

\subsection{Basic method}

\subsubsection{Model preparation}

We mainly consider according to the level of economic development, social equity and environmental sustainability. We select the key factors that affect the sustainable development of the city as the evaluation factor. We define material element as

$$
\mathbf{R}=(L, M, X)=\left(\begin{array}{ccc}
L & M_{1} & X_{1} \\
& M_{2} & X_{2} \\
& \vdots & \vdots \\
& M_{n} & X_{n}
\end{array}\right)
$$

\subsubsection{Calculate the correlation}

According to the correlation function, the correlation of $\mathbf{R}_{\mathbf{0}}$ for $L_{j}$ is

$$
\lambda_{j}\left(L_{0}\right)=\sum_{i=1}^{n} \omega_{i} K_{j}\left(x_{i}\right)
$$

We determine $\omega_{i}$ based on AHP.

$$
K_{j}\left(x_{i}\right)= \begin{cases}\frac{-\rho\left(x_{i}, X_{0 i j}\right)}{\left|X_{0 i j}\right|}, & x_{i} \in X_{0 i j} \\ \frac{\rho\left(x_{i}, X_{0 i j}\right)}{\rho\left(x_{i}, X_{i j}\right)-\rho\left(x_{i}, X_{0 i j}\right)}, & x_{i} \notin X_{0 i j}\end{cases}
$$




$$
\begin{gathered}
\rho\left(x_{i}, X_{0 i j}\right)=\left|x_{i}-\frac{\left(a_{0 i j}+b_{0 i j}\right)}{2}\right|-\frac{\left(b_{0 i j}-a_{0 i j}\right)}{2} \\
\rho\left(x_{i}, X_{i j}\right)=\left|x_{i}-\frac{\left(a_{i j}+b_{i j}\right)}{2}\right|-\frac{\left(b_{i j}-a_{i j}\right)}{2}
\end{gathered}
$$

\subsubsection{Comprehensive analysis}

We substitute the actual data into (1) and we get $\lambda_{j}\left(L_{0}\right)$.

- If $\lambda_{j}=\max \left\{\lambda_{j}\left(L_{0}\right), j=1,2, \cdots, n\right\}>0$, the level of sustainable development of the city is $L_{j}$

- If $\lambda_{j}\left(L_{0}\right) \leq 0$ for all $j$, it indicates that the level of sustainable development of the city is out of range, we should adjust the parameters and weight factors, and then conduct a reasonable assessment.

\subsection{Extension comprehensive evaluation of urban smart growth}

\subsubsection{Evaluation factors and classification options}

Our assessment is based on the ten principles of "smart growth" proposed in 1990. From the connotation of different elements, mixed with the use of land and maximize the use of compact building design is the level of urban land structure design indicators, reflecting the level of economic prosperity. The remaining principles relate to improvements in social equity and environmental sustainability. To this end, this paper, based on the international smart growth evaluation index system, increases GDP, per capita road area and many other indicators to evaluate the smart growth of different cities.

We define three sub-targets, which are economic development capacity $Y_{1}$, social equality $Y_{2}$ and environmental sustainability $Y_{3}$.We record their weight as $\omega_{i}(i=1,2,3)$. And we establish more detailed indicators $Y_{i j}(i=1,2,3 ; j=1,2, \cdots, 6)$ as $M_{i}(i=1,2, \cdots, 15)$.

we get a city of any of the 15 measured data corresponding to four levels of development, and then we get four assessed material elements, which are

$$
\mathbf{R}_{\mathbf{0}}=\left(\begin{array}{ccc}
L_{i} & M_{1} & x_{1} \\
& M_{2} & x_{2} \\
\vdots & \vdots \\
M_{15} & x_{15}
\end{array}\right), i=1,2,3,4
$$

\subsubsection{Determine the weight of the evaluation factor}

We take the weights of the corresponding four evaluation factors of $\omega_{3}$ as an example and get their weights.

Relative to the overall goal, the relative importance of the three sub-targets is shown in Table 1

Table 1 Sub-target judgment matrix

\begin{tabular}{c|ccc}
\hline$Y_{i}$ & $Y_{1}$ & $Y_{2}$ & $Y_{3}$ \\
\hline$Y_{1}$ & 1 & 2 & 3 \\
$Y_{2}$ & $1 / 2$ & 1 & 2 \\
$Y_{3}$ & $1 / 3$ & $1 / 2$ & 1 \\
\hline
\end{tabular}

The eigenvectors corresponding to the largest eigenvalues of the judgment matrix $\mathbf{A}=\left(\begin{array}{ccc}1 & 2 & 3 \\ 1 / 2 & 1 & 2 \\ 1 / 3 & 1 / 2 & 1\end{array}\right)$, then we normalize it and get $(0.5396,0.2970,0.1634)$. As above, we can get the weights of $Y_{1,2,3}$, which are $\omega=\left(\omega_{1}, \omega_{2}, \omega_{3}\right) \neq, 0 . \$ 3960.29700 .1634$. 
For the third sub-goal, the relative importance of the four evaluation factors is shown in Table 2.

Table 2 Evaluation factor judgment matrix

\begin{tabular}{c|cccc}
\hline$Y_{i j}$ & $Y_{31}$ & $Y_{32}$ & $Y_{33}$ & $Y_{34}$ \\
\hline$Y_{31}$ & 1 & $1 / 3$ & 2 & 3 \\
$Y_{32}$ & 3 & 1 & 2 & 1 \\
$Y_{33}$ & $1 / 2$ & $1 / 2$ & 1 & 3 \\
$Y_{34}$ & $1 / 3$ & $1 / 3$ & $1 / 3$ & 1 \\
\hline
\end{tabular}

Similarly, we calculate the relative weights between the four evaluation factors, which are

$$
\omega_{3}=\left(\omega_{31}, \omega_{32}, \omega_{33}, \omega_{34}\right)=(0.279,0.336,0.228,0.157)
$$

The specific weights of the four evaluation factors of the third sub-goal are

$$
M_{12,13,14,15} \neq 0.0460 .0550 .0370 .026
$$

As above, we obtain the specific weights of the other 10 evaluation factors. As shown in Table 3. Table 3 The weights

\begin{tabular}{c|cccccccc}
\hline factor & $M_{1}$ & $M_{2}$ & $M_{3}$ & $M_{4}$ & $M_{5}$ & $M_{6}$ & $M_{7}$ & $M_{8}$ \\
\hline weight & 0.178 & 0.065 & 0.151 & 0.059 & 0.086 & 0.068 & 0.056 & 0.053 \\
\hline factor & $M_{9}$ & $M_{10}$ & $M_{11}$ & $M_{12}$ & $M_{13}$ & $M_{14}$ & $M_{15}$ & \\
\hline weight & 0.042 & 0.036 & 0.042 & 0.046 & 0.055 & 0.037 & 0.026 & \\
\hline
\end{tabular}

\section{Conclusions}

In our paper, we study the ten principles of smart growth and the connotation of three "E". Considering the subjective defects of AHP, we use the matter-element theory of extension mathematics to establish a complete index system. And we translate qualitative principles into 15 quantitative indicators. We set four levels for the city's smart growth success, which are "best, better, general and poor”.

\section{Acknowledgments}

At the very moment of finishing this paper, I'd like to express my gratitude to my lovely and beautiful supervisor, Ms.Gu. Ms.Gu helped me in material researching, material arranging and thesis format writing. Without her selfless devotion, I can't complete this essay.

\section{References}

[1] EPA, “This is Smart Growth.” 2016

[2] EPA, "Smart Growth: A Guide to Developing and Implementing Greenhouse Gas Reductions Programs.” 2011.

http://www.sustainablecitiesinstitute.org/Documents/SCI/Report_Guide/Guide_EPA_SmartGrowth GHGReduction_2011.pdf 